\title{
Alignment of Vertically Grown Carbon Nanostructures Studied by X-Ray Absorption Spectroscopy
}

\author{
Jeannot Mane Mane1,2, François Le Normand ${ }^{1}$, Rolant Eba Medjo ${ }^{3,4}$, Costel Sorin Cojocaru', \\ Ovidiu Ersen1, Antoine Senger ${ }^{1}$, Carine Laffon ${ }^{5}$, Bridinette Thiodjio Sendja ${ }^{2,3}$, \\ César Mbane Biouele ${ }^{3}$, Germain Hubert Ben-Bolie ${ }^{3}$, Pierre Owono Ateba ${ }^{3}$, Philippe Parent ${ }^{5}$ \\ ${ }^{1}$ IPCMS, UMR 7504 CNRS, Strasbourg, France \\ ${ }^{2}$ Ecole Nationale Supérieure Polytechnique (National Advanced School of Engineering), Department \\ of Mathematics and Physical Sciences, The University of Yaoundé I, Yaounde, Cameroon \\ ${ }^{3}$ Physics Department, Faculty of Science, University of Yaoundé I, Yaounde, Cameroon \\ ${ }^{4}$ Physics Department, Faculty of Science, University of Douala, Douala, Cameroon \\ ${ }^{5}$ LURE, UMR CNRS, Centre Universitaire Paris Sud, Orsay, France \\ Email: jeannotmane@yahoo.fr
}

Received 1 September 2014; revised 18 October 2014; accepted 2 November 2014

Copyright (C) 2014 by authors and Scientific Research Publishing Inc.

This work is licensed under the Creative Commons Attribution International License (CC BY).

http://creativecommons.org/licenses/by/4.0/

(c) $\underset{\mathrm{EY}}{\mathrm{B}}$ Open Access

\section{Abstract}

X-Ray Absorption Spectroscopy (XAS) on the carbon K edge of carbon nanostructures (nanotubes, nanofibers, nanowalls) is reported here. They are grown on plain SiO2 (8 $\mathrm{nm}$ thick)/Si(100) substrates by a Plasma and Hot Filaments-enhanced Catalytic Chemical Vapor Deposition (PE HF CCVD) process. The morphology and the nature of these carbon nanostructures are characterized by SEM, TEM and Raman spectroscopy. According to conditions of catalyst preparation and DC HF CCVD process, carbon nanotubes (CNTs), carbon nanofibers (CNFs), carbon nanowalls (CNWs), carbon nanoparticles (CNPs) with different orientation of the graphene plans or shells can be prepared. From the angular dependence of the incident light and geometrical morphology of the nanostructures, wide variations of the $\mathrm{C}$ K-edge intensity of the transitions to the empty $\pi^{*}$ and $\sigma^{*}$ states occur. A full lineshape analysis of the XAS spectra has been carried out using a home-made software, allowing estimating the relative proportion of $\pi^{*}$ and $\sigma^{*}$ transitions. A geometrical model of the angular dependence with the incidence angle of the light and the morphology of the carbon nanostructures is derived. With normalization to the HOPG (Highly Oriented Pyrolytic Graphite graphite) reference case, a degree of alignment can be extracted which is representative of the localized orientation of the graphitic carbon $\pi$ bonds, accounting not only for the overall orientation, but also for local defects like impurities incorporation, structural defects ... This degree of alignment shows good agreement with SEM observations. Thus CNTs films display degrees 
of alignment around $50 \%$, depending on the occurrence of defects in the course of the growth, whereas no special alignment can be detected with CNFs and CNPs, and a weak one (about 20\%) is detected on CNWs.

\title{
Keywords
}

\author{
X-Ray Absorption Spectroscopy, Carbon Nanostructures (CNTs, CNFs, CNWs, CNPs), Plasma- and \\ Hot Filaments-Enhanced Catalytic Chemical Vapor Deposition, Geometrical Model, Angular \\ Dependence
}

\section{Introduction}

Carbon nanotubes (CNTs) have attracted an enormous interest since their first report by Iijima in 1991 [1] for their outstanding properties. Their highly anisotropic form suggests they may be considered as nearly 1D nanomaterials. Hence a special attention has been devoted to the electron field emission from CNTs. In this specific case, the very high aspect ratio is expected to markedly decrease the emission threshold at the top of the nanotube. From the many studies devoted to this important property, it has been concluded that the CNTs must be i) well aligned, but ii) with a scarce and regular density in order to prevent the screening of field emission by the nanotubes just in the vicinity [2]. This infers a considerable amount of literature on the growth of oriented nanotubes aligned in the direction normal to a flat surface. A variety of catalytic CVD (CCVD) techniques were used [3]. The origin of this alignment could be manifold. Mutual long range van der Waals interactions between CNTs keep the vertical alignment throughout the growth, but this mechanism can state only for highly dense films where screening of field emission is expected to occur. On films grown by plasma-enhanced CCVD (PE CCVD) processes, the role of the electric field is underlined with a reported threshold for alignment beyond around $1 \mathrm{~V} / \mathrm{mm}$ [4]. Conformal growth can also be used but the substrate preparation is generally tedious [5]. In addition the alignment is also important when nanotubes are spun [3]. However despite its importance, there are to our knowledge not so many quantitative studies on the mutual orientation of vertically-grown CNTs on a flat surface. Generally, SEM images provide a valuable but only qualitative overview of alignment. Moreover TEM examinations generally reveal many defects that may lead to deviations in the mean growth direction of the CNTs and even to some entanglement [6]. Film thinning for side-view TEM observations is tedious and damages cannot be excluded. Few other techniques have been used to more deeply study the mutual alignment of CNTs, such as X-Ray diffraction (XRD) [7] [8], but the information provided by the intensity of the (002) pattern is not very sensitive to the vertical alignment and the local order, or Grazing Incidence Small Angle X-ray Scattering (GISAXS) [6], but the information is indirectly extracted through a complex analytic procedure. $\mathrm{X}$-ray absorption spectroscopy (XAS) recorded on the carbon K-edge is a powerful tool to provide chemicallyselective information on the local environment around carbon in solid materials, like CVD diamond [9]-[14], amorphous carbon nitride [15]-[19], amorphous graphitic carbon [20] [21] and CNTs [22]-[26], but the technique is also suitable to probe the adsorption of functional organic molecules with information both on the distance and the orientation of the bond [27] [28]. This property is due to the angular dependence of the absorption transition. This angular dependence had been reported on graphite since a long time [29] and the analysis has been further refined both on an experimental and a theoretical points of view [30] [31]. The $\pi^{*}$ antibonding state corresponds to the out-of-plane bonds in the $\mathrm{sp}^{2}$ bonding configuration and exhibits a strong polarization dependence. According to the absorption process, the signal is maximum when the direction of the electric field of the incident light matches the direction of unfilled orbitals [32]. Owing to the alignment of carbon nanotubes, a specific orientation of the $\pi$ bond is expected and the absorption on the C K-edge would present an angular selectivity when considering the specific $1 \mathrm{~s} \rightarrow \pi^{*}$ transition and, in a less extent, the $1 \mathrm{~s} \rightarrow \sigma^{*}$ transition. Moreover the XAS signal would be sensitive to the global film orientation. Accordingly this local probe would be sensitive to chemical impurities, defects, chemical adsorption, curvature-induced orbital rehybridization. Previous papers have been reported on the angular dependence at the $\mathrm{C} K$ edge from Multi Wall CNT (MWCNT) films grown by classical thermal CCVD (T CCVD) [33] [34], or by plasma-enhanced CCVD [35], and Single Wall CNT (SWCNT) "bucky paper" [36]. However on CNT films, orientation effects are poorly evidenced, 
whereas on "bucky paper" an in-plane preferred orientation can be evidenced. In this paper, we report on a study of the angular dependence at the XAS C K edge concerning films of multiwall carbon nanotubes (MWCNTs), carbon nanofibers (CNFs), carbon nanoparticles (CNPs) and carbon nanowalls (CNWs). They are grown by a plasma-enhanced CCVD process. They are otherwise characterized by Scanning Electron Microscopy (SEM), Transmission Electron Microscopy (TEM) and Raman spectroscopy. It is found that indeed the XAS spectra of CNTs, instead of CNFs, CNPs or CNWs, show a strong angular variation in a way that is reverse to the behaviour of graphite. From a full geometrical description of the morphology of the films as well as the orientation of the graphene shells inside the nanostructures, it is even shown that a semi-quantitative measurement of the alignment of the nanotubes can be obtained. In addition, it is reported that the carbon nanostructures are highly sensitive to a previous in situ thermal treatment, as an intense adsorption on the outer wall of the nanotubes may strongly affect the absorption

\section{Experimental}

The different steps of the substrate treatments and CNT growth are recalled in Ref. [37] [38].

\subsection{Substrate Sample Preparation TM/SiO2/Si(100)}

The samples were prepared by deposition of a $\mathrm{SiO} 2$ layer (thickness $8 \mathrm{~nm}$ ) by a Double Electron Cyclotron Resonance (DECR) plasma process on a $\operatorname{Si}(100)$ sample ( $\mathrm{Sb} \mathrm{n}$-doped with $\rho=3 \mathrm{~m} \Omega \cdot \mathrm{cm}$ size $8.5 \times 6 \times 0.245 \mathrm{~mm}^{3}$ ). $\mathrm{SiO} 2$ was evaporated on $\mathrm{Si}(100)$ for two main reasons: it is a protective barrier layer that prevents the formation of transition metal silicide through direct interaction with silicon, and $\mathrm{SiO} 2$ is a non-wetting substrate that is convenient for transition metal diffusion and aggregation. However the thickness of the $\mathrm{SiO} 2$ layer must be thin enough to allow electron conduction through tunnelling for field emission measurements. The sample $\mathrm{SiO} 2 /$ $\mathrm{Si}(100)$ was then transferred into a stainless steel Ultra High Vacuum (UHV) preparation chamber (base vacuum 10 - 10 mbar) where transition metal (TM Co or Fe or a mixture of them) evaporation was performed without air removal. Co (Fe) of grade 99.995 was evaporated with an OMICRON EFM3 effusive source at a pressure within $7-10 \times 10^{-10}$ mbar on the sample heated at $925 \mathrm{~K} \pm 20 \mathrm{~K}$ during $30 \mathrm{~min}$. The flux rate at $973 \mathrm{~K}$ is estimated to $0.025 \mathrm{~nm}$ of equivalent layer per minute from an in situ XPS analysis of the Co2p/Si2p signal. In other cases the transition metal is deposited by sputtering within conditions that have been elsewhere described [39].

\subsection{CNTs Growth by the DC HF CCVD Process}

As well, the CNTs growth method using a direct current plasma and hot filaments-enhanced catalytic chemical vapor deposition (DC HF CCVD) process has been fully described elsewhere [37]. After the catalyst evaporation, the samples were further transferred into an UHV CVD chamber for the growth of the carbon nanostructures (base pressure lower than $10^{-9} \mathrm{mbar}$ ). The gas mixture (100 sccm C2H2:H2:NH3) was thermally activated by hot filaments (up to a power $\mathrm{Pf}=150 \mathrm{~W}$ ) and kinetic energy-activated by polarisation between tantalum grid electrodes with the cathode grid in front of the sample at $V_{P}=-300 \pm 10 \mathrm{~V}$. The discharge was ignited and stabilized by the electron emission of the hot filaments. This ensured a high concentration of ionic species as well as activated radicals in front of the sample. A small additional negative extraction voltage $\left(V_{e}=10 \mathrm{~V}\right)$ was put on the sample, which allowed withdrawing a controlled current of ionic species onto the sample $\left(I_{e}\right)$, with extraction power $P_{e}=I_{e} * V_{e}$. The temperature $(973 \mathrm{~K})$ was controlled and regulated by an independent infrared heater set on the rear side of the sample. A Pt/PtRh thermocouple was contacting the rear side of the sample during the temperature rise. This thermocouple was switched off when the polarisation was started. The contact was then used to monitor the electric current onto the sample due to the discharge. The sequences of deposition were the followings: the sample was first heated under vacuum $(10 \mathrm{~K} / \mathrm{min}, 573 \mathrm{~K}, 10 \mathrm{~min})$, then the temperature was risen to $973 \mathrm{~K}(10 \mathrm{~K} / \mathrm{min} ; 40 \mathrm{~min})$ in a $\mathrm{H} 2$ atmosphere at $15 \mathrm{mbar}$. Acetylene and ammonia were introduced. Subsequently the primary discharge and the extraction discharge onto the sample were adjusted to the desired values. The extraction current Ie was set constant throughout the deposition process.

To stop the CNTs growth, the acetylene feedthrough, the polarisation, the filaments and finally the hydrogen feedthrough were subsequently switched off. The references as well as the main characteristics of the sample preparation are displayed in Table 1. According to the nature, the mode of deposition of the catalyst as well as 
the pressure of the reactive gas mixture, the temperature, the hot filaments power and the plasma power, different carbon nanostructures were allowed to growth, as listed in the following Table 2. Highly HOPG was purchased from Union Carbide.

\subsection{Surface Analyses, Morphological and Structural Characterizations}

TEM observations were performed on a TOPCON 002B microscope operating at $200 \mathrm{kV}$. The samples were scratched with a diamond tip and the material was directly pulled onto an amorphous carbon membrane drilled with holes for direct observations. SEM observations were performed on an XL30S-FEG PHILIPPS working at $3 \mathrm{kV}$. The nature of the carbon deposit was probed by Raman spectroscopy on a Renishaw apparatus with a He-Ne light source. More structural and spectroscopic data are reported in [39].

\subsection{X-Ray Absorption Spectroscopy (XAS) Experiments}

C K-edge measurements were performed at the Laboratoire pour l'Utilisation du Rayonnement Electromagnétique (LURE, ORSAY, France) on the VUV Super-Aco storage ring. They were carried out on the SACEMOR beam line [12] [40] using a high energy TGM monochromator (1200 lines $\cdot \mathrm{mm}^{-1}$ grating, resolution better than $0.2 \mathrm{eV}$ at the $\mathrm{C} \mathrm{K}$-edge). The base vacuum was around $10-9$ mbar. The carbon surface contamination by the optics

Table 1. Main preparation characteristics of carbon nanostructures grown on $\mathrm{SiO}_{2}(5 \mathrm{~nm}) / \mathrm{Si}(100)$ samples. Other conditions are: $\mathrm{C}_{2} \mathrm{H}_{2}: \mathrm{H}_{2}: 20: 80$; distance filaments-substrate: $5 \mathrm{~mm}$; gas flow: $100 \mathrm{sccm}$.

\begin{tabular}{ccccccccc}
\hline Sample & Catalyst & $\begin{array}{c}\text { TM Deposition Process } \\
\text { S: sputtering; E: evaporation }\end{array}$ & $\mathrm{TM} / \mathrm{Si}$ & $\mathrm{P}_{\mathrm{f}}(\mathrm{W})$ & $\mathrm{P}_{\mathrm{e}}(\mathrm{mW})$ & $\begin{array}{c}\text { Pressure } \\
(\mathrm{mbars})\end{array}$ & $\mathrm{T}(\mathrm{K})$ & Nanostructure \\
\hline I Nanot 24 & Co & $\mathrm{S}$ & 150 & 10 & 15 & 973 & CNFs with grapheme//substrate \\
II Nanot 29 & Co & $\mathrm{S}$ & & 150 & 30 & 15 & 973 & CNTs (poorly oriented) \\
III Nanot 30 & Co & E & 0.33 & 150 & 30 & 15 & 973 & CNFs with graphene $\perp$ substrate \\
IV Nanot 31 & Co & E & 0.87 & 150 & 30 & 15 & 973 & CNTs \\
V Nanot 36 & Co & E & & 100 & 20 & 15 & 973 & CNPs \\
VI Nanot 42 & Co & E & & 145 & 20 & 15 & 1083 & CNTs (highly oriented) \\
VII FLN1 & Co & E & 140 & 20 & 15 & 973 & CNTs (medium oriented) \\
VIII FLN2 & Co-Fe & E & E & 140 & 20 & 15 & 973 & CNTs (highly oriented) \\
IX FLN4 & Co & & 140 & 20 & 5 & 973 & CNWs \\
\hline
\end{tabular}

Table 2. Main characteristics of the carbon nanostructures grown CNTs, CNFs, CNPs and CNWs are carbon nanotubes, nanofibers, nanoparticules and nanowalls, respectively.

\begin{tabular}{|c|c|c|c|c|c|}
\hline Samples & Nanostructure & Outer diameter $(\mathrm{nm})$ & Inner diameter $(\mathrm{nm})$ & Length $(\mathrm{nm})$ & Density $\left(\mu \mathrm{m}^{-2}\right)$ \\
\hline I & CNFs with grapheme//substrate & 25 & 0 & $110 /$ & 472 \\
\hline II & CNTs (poorly oriented) & & & & \\
\hline III & CNFs with graphene $\perp$ substrate & 20 & 0 & $140 /$ & 494 \\
\hline IV & CNTs & 30 & 9 & $375 /$ & 400 \\
\hline V & CNPs & & & & \\
\hline VI & CNTs (highly oriented) & 25 & 5 & $400 /$ & 349 \\
\hline VII & CNTs (small oriented) & & & $<100$ & \\
\hline VIII & CNTs (highly oriented) & 10 & 4 & $187 /$ & 1000 \\
\hline IX & CNWs & & & & \\
\hline
\end{tabular}


of the line does not exceed $1 \%$ of the total signal and can be neglected for materials with a high carbon concentration. The spectra were recorded in the total-electron-yield detection (TEY) and partial electron yield (PEY), the last being expected to be less surface-sensitive. Experiments were carried out in two experimental configurations according to the angle $\alpha$ between the sample and incidence of the light: at normal incidence $\left(\alpha \approx 0^{\circ}\right.$ with electric field vector $\boldsymbol{E}$ parallel to the surface, $\alpha=(\boldsymbol{P}, \boldsymbol{C})$ and at grazing incidence $(\alpha \approx 90-10)^{\circ}$ with $\boldsymbol{E}$ nearly normal to the surface. The angular variations of the intensity of the $\mathrm{C} \mathrm{K}$ edge transitions to the $\sigma^{*}$ and $\pi^{*}$ unoccupied states were monitored at these two incidence angles, respectively (Scheme 1). The step was $0.1 \mathrm{eV}$. The spectra were normalized to the spectrum of a copper grid freshly coated with gold. The energies were calibrated to the carbon ionisation potential (IP). Owing to this calibration procedure, the error on the C K-edge is expected to be no more than $0.2 \mathrm{eV}$. The energy step was $0.1 \mathrm{eV}$. The base pressure in the chamber was $2 \times 10^{-10}$ Torr. The samples were analyzed as such after introduction within the XAS chamber and after a subsequent in situ cleaning by electron bombardment at $500^{\circ} \mathrm{C}$ for 2 hours.

The spectra were first corrected for the background by substracting it on the preedge low energy side with a linear background contribution. Then the spectra were normalized with regard to the preedge intensity on one side $\mu_{0}$, and to the absorption intensity $\mu(320)$ at $320 \mathrm{eV}$ on another side, according to $I=\left\{\left[\mu-\mu_{0} /\left[\mu(320)-\mu_{0}\right]\right]\right\}$. Above this energy range, oscillations due to extended $x$ ray-absorption fine structure (EXAFS) occur. Lineshape analyses of the individual transitions were carried out using a home-made software. The spectra were deconvoluted by a procedure where each feature was broadened by a variable Voigt function including an overall gaussian broadening accounting for the experimental resolution set to $0.75 \mathrm{eV}$, a variable gaussian broadening accounting for electron-phonon interactions, amorphisation effects and the width of the final states distribution, and a lorentzian broadening accounting for the lifetime of the core hole fixed to $0.21 \mathrm{eV}$ for the $\mathrm{C} \mathrm{K}$ edge [41]. Heavyside step functions broadened by the gaussian experimental resolution were added to these individual contributions. They were located at the threshold of the $1 \mathrm{~s} \rightarrow \pi^{*}$ and $1 \mathrm{~s} \rightarrow \sigma^{*}$ absorption transitions, respectively, and they accounted for absorption transitions to the continuum of empty states. Inadequate energy resolution, uncertain normalization process and non-attributed features result in relevant uncertainties in the determination of the intensities.

\section{Results}

\subsection{Morphological, Structural and Spectroscopic Investigations on Carbon Nanostructures Grown by PE-HF-CCVD}

As the SEM and TEM images clearly illustrate in Figure 1 and Figure 2, respectively, the carbon nanostructures prepared in this study display widely different morphologies according to some variable parameters of the

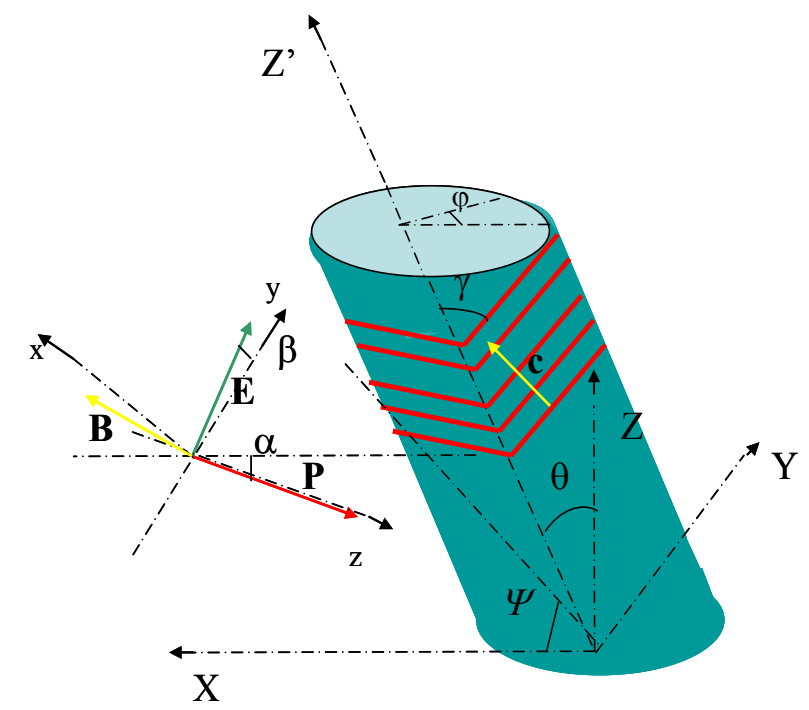

Scheme 1. Geometrical model of the light irradiation of carbon nanotubes of mean orientation on a flat surface. 


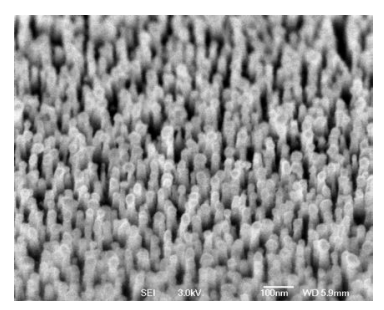

(a)

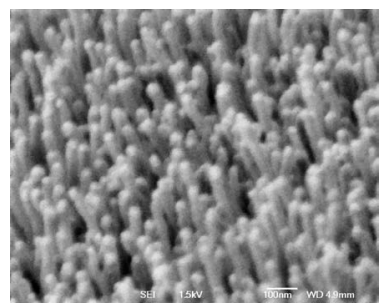

(d)

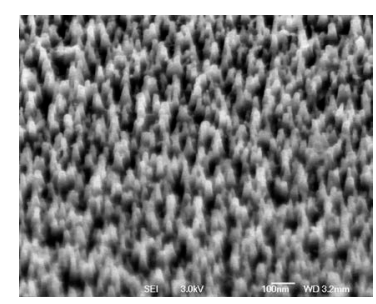

(b)

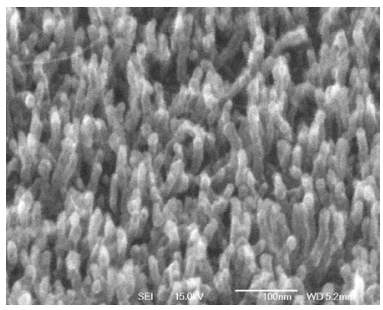

(e)

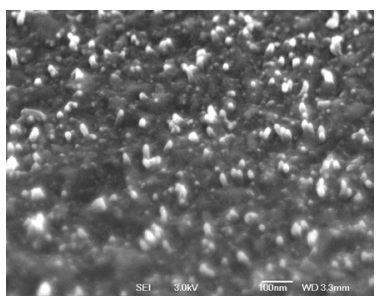

(c)

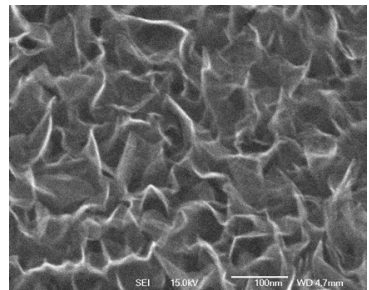

(f)

Figure 1. SEM images of carbon nanostructures: (a) sample I; (b) sample III; (c) sample V; (d) sample IV; (e) sample VIII; (f) sample IX.

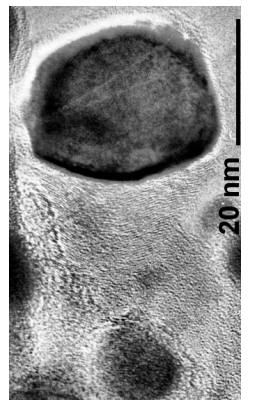

(a)

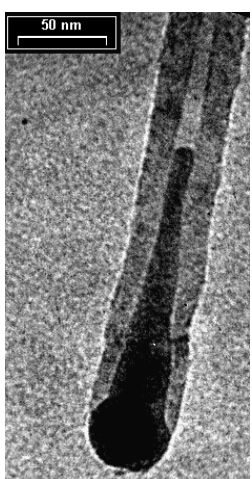

(d)

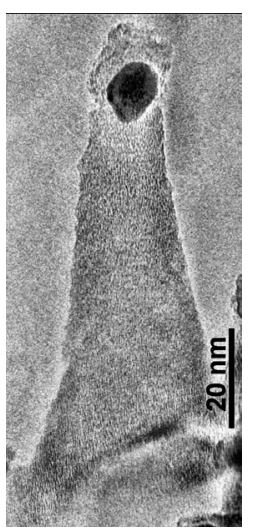

(b)

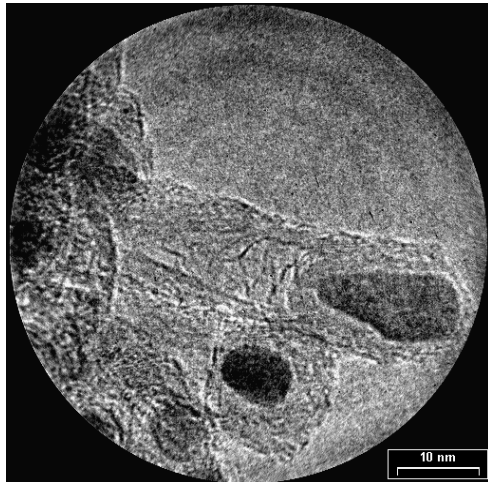

(e)

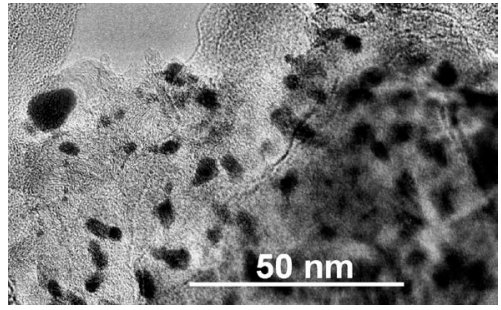

(c)

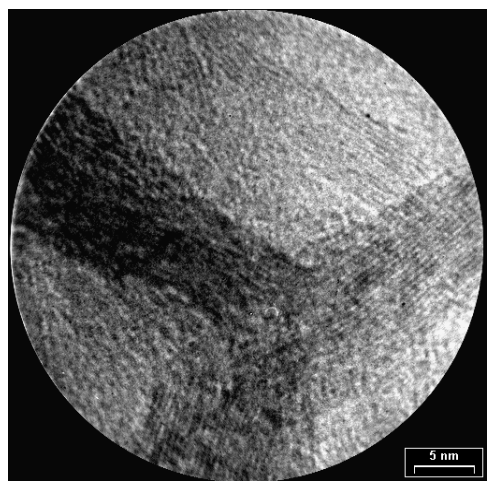

(f)

Figure 2. TEM images of carbon nanostructures: (a) sample I; (b) sample III; (c) sample V; (d) sample IV; (e) sample VIII; (f) sample IX.

catalyst preparation (amount of cartalyst deposited measured by the surface ratio $\mathrm{Co} / \mathrm{Si}$, mode of Co deposition, and growth conditions (temperature, plasma power and hot filaments power, pressure)) reported in Table 1. Under conditions where the catalyst is deposited by UHV atomic evaporation at moderate pressure ( 5 - 15 mbar), it 
is possible to control the nature of the carbon nanostructures [39]. Carbon nanowalls (CNWs) are prepared at low pressure (5 mbar) (Figure 1(f)).

These are graphene sheets that merge in the direction normal to the surface (Figure 2(f)), when the energy of the ions impinging the surface is rather high. Carbon nanoparticules (CNPs) are prepared when the power of the hot filaments is low (Figure 1(c) and Figure 2(c)). Carbon nanofibers were prepared under different conditions. When the plasma power is high and the catalyst surface concentration is low, then graphene sheets grow in a direction normal to the surface (Figure 1(b) and Figure 2(b)), forming conical nanostructures with the metal particle on top of it. When the catalyst is prepared by sputtering and the plasma power is rather low, then CNFs can grow with graphene sheets parallel to the surface (Figure 1(a) and Figure 2(a)). Strong adhesion of the catalyst to the substrate and low energy ions can explain this mode of growth. Within medium plasma power, carbon nanotubes can yet be grown with graphitic planes in a parallel direction to the fiber axis can yet be prepared (Figure 2(d)). These samples however display different mutual orientation. Highly oriented films are obtained under optimized conditions (Figure 1(d)). Poorly oriented films are also obtained (Figure 1(e)) and the nanotubes show more defects (Figure 2(e)). Anyway the presence of hot filaments heated around $2200 \mathrm{~K}$ must be stressed.

They provide hydrogen radicals that are very reactive towards all kinds of amorphous carbon. This is checked in Raman spectra (Figure 3). The most intense Raman spectrum corresponds to sample $\mathrm{V}$ as the etching of carbon by hydrogen radicals is less effective. Thus probably carbon not only surrounds the particle but also is spread onto the surface of the sample. It is beyond the scope of this paper to discuss the Raman spectra of these different carbon nanostructures. We must just underline that whatever the sample the $\mathrm{D}$ band due to disordered carbon and the $\mathrm{G}$ band due to the main tangential vibrations in graphene sheets or shells are very narrow. This indicates that the carbon deposit is selective

\subsection{Graphite XAS Spectra}

To ascertain the reliability of the analysis of CNTs XAS spectra, the XAS spectra of HOPG sample is first recorded. Graphite, with its layered structure and large interlayer separation, is often modelled as a two-dimensional solid. In addition, the knowledge of the properties of graphite is a starting point for understanding the structure and properties of many new carbon nanostructures like nanotubes. The two-dimensional nature of graphite results in a strong directionality of the orbitals: $\sigma$ orbitals lie within the basal plane, while $\pi$ orbitals are directed perpendicular to this basal plane along the $c$ axis. By tuning the incidence angle of the polarized synchrotron light on the sample $\alpha$, it is possible to excite final states of specific symmetry at the carbon $\mathrm{K}$ edge. According to the Fermi gold rule and the dipole selection rules, when the electric field vector $\boldsymbol{E}$ lies within the basal plane (i.e. perpendicular to the $\boldsymbol{c}$ axis $(\boldsymbol{E} \perp \boldsymbol{c})$, then $\sigma^{*}$ final states are selected. When the $\boldsymbol{E}$ vector is perpendicular to the plane (i.e. parallel to the $\boldsymbol{c}$ axis $(\boldsymbol{E} / / \boldsymbol{c})$, then final states of $\pi$-symmetry are excited. Thus the intensity of each transition will strongly depend on the angle $\alpha$ between the electric field vector $\boldsymbol{E}$ and the $c$ axis. Using calculations of density of states (DOS), it has been possible to assign the features of the $\mathrm{C}(\mathrm{K})$ absorption structure (XAS) to specific states of the Brillouin zone in the theoretical band structure of

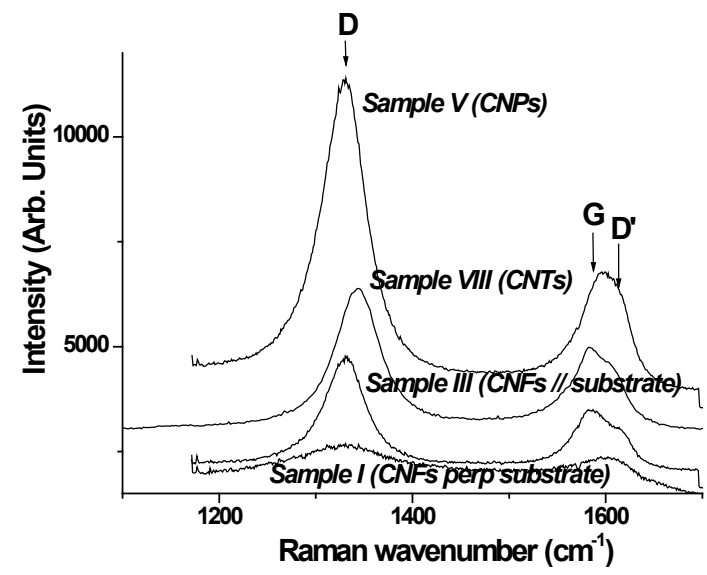

Figure 3. Raman spectra of carbon nanostructures. 
graphite [29]-[31]. Moreover, by monitoring the angular dependence of the spectral features of the carbon K edge, the symmetries of the final states were determined. Therefore, in the single-crystal graphite, the intensity of a pure $1 \mathrm{~s} \rightarrow \pi^{*}$ transition at $285 \mathrm{eV}$ is shown to be proportional to $\sin ^{2} \alpha$ (with its maximum at glancing incidence), while the intensity of a pure $1 \mathrm{~s} \rightarrow \sigma^{*}$ transition is shown to be proportional to cos 2 with its maximum at normal incidence) [29]. As a result of this behaviour, the assignments (energy, symmetry, location in Brillouin-zone regions) of the main features in the carbon K edge spectrum of HOPG graphite are determined in agreement with the assignments reported in [29] [31] (Figure 4) and the results are reported in Table 3. In this fitting procedure, the energy and the width of the lorentzian line, quoted to $0.21 \mathrm{eV}$, are fixed, whereas gaussian shapes of different width for each contribution were allowed to vary. It is clear that the occurrence of these transitions is related to the unoccupied density of states (UDOS) and to final state effects. Thus the physical meaning of the different contributions introduced is not warranted. Nevertheless it is clear that the full absorption spectra can be divided into three regions. At $285.5 \mathrm{eV}$ the peak named A corresponds to the transition towards unoccupied $\pi_{0}$ states near Q in the Brillouin zone at $2 \mathrm{eV}$ above the Fermi level [29]-[31] [42] [43], strongly dependent on the incident angle. The second region within $286.5-292.5 \mathrm{eV}$ corresponds to the free electron like interlayer states [22] [27] [30] [43] and adsorbed or chemisorbed molecular states [22] [23] [27] [30] [32] [36] [43]. They are strongly dependent on the chemical treatment of the sample, as indicated in Figure 5 on sample III before and after an in situ thermal treatment at $500^{\circ} \mathrm{C}$.

In this energy range the contributions of $1 \mathrm{~s} \rightarrow \pi^{*}$ and $1 \mathrm{~s} \rightarrow \sigma^{*}$ transitions are due to adsorbed functionalized states such as $\mathrm{C}-\mathrm{O}-, \mathrm{C}-\mathrm{H}, \mathrm{C}=\mathrm{O}, \mathrm{C}-\mathrm{OH} \ldots$ They are due to the adsorption of various molecules like water, $\mathrm{CO}, \mathrm{CO}_{2}$ or hydrocarbons. HOPG XAS spectra exhibit a $\sigma^{*}$ exciton at $291.6 \mathrm{eV}$ corresponding to a $\mathrm{C}-\mathrm{H}^{*}$ bond resonance [23] [24] [30] [43]. The presence of a $\sigma^{*}$ exciton at $291.6 \mathrm{eV}$ points to a material with well-formed local bonding configuration or good short-range order. This line, which is an atomic-like transition, is used to ascertain the lorentzian width due to the lifetime of the core-hole. Moreover the small shoulder at 286 - $287 \mathrm{eV}$ may also be attributed to a singularity in the DOS of graphite [29]. Another explanation of these lines could be the presence of free-electron-like interlayer states (FELI) in the graphite with $\sigma$-symmetry [30]. The third region above $291.8 \mathrm{eV}$ corresponds to transitions towards empty states of $\sigma^{*}$ and $\pi^{*}$ symmetry states. The assignations of these states closely agree the features of the conduction band diagram as reported in Figure 4. Moreover the angular dependence allows to distinguish between $\sigma^{*}$ symmetry from $\pi^{*}$ symmetry states. Thus at a grazing incidence $\left(\pi / 2-\alpha=15^{\circ}\right)$, in addition to the peak $\mathrm{A}$, other transitions with a $\pi$-symmetry are involved in transitions named $\mathrm{C}$ and $\mathrm{H}$ at $295.5 \mathrm{eV}$ and at $316.5 \mathrm{eV}$ which might correspond to $\pi_{0}$ or $\pi_{1}$ final states near $\Gamma$ and to $\pi_{4}$ final state near Q in the Brillouin zone, respectively. In agreement with these assignations these contributions are maxima at this incidence angle. Reversely from the normalized carbon $\mathrm{K}$ edge spectrum of HOPG at normal incidence (Figure 6(a)), the B, D, E, F and G spectral features at $292.5 \mathrm{eV}, 297.8$ $\mathrm{eV}, 303.5 \mathrm{eV}, 307,5 \mathrm{eV}$ and $311.4 \mathrm{eV}$, respectively, are mainly transitions to the $\sigma^{*}$ unoccupied final states. They are $\sigma_{1}, \sigma_{2} ; \sigma_{3}-\sigma_{6} ; \sigma_{7} ; \sigma_{9}$ and $\sigma_{10}$ states in the Brillouin zone $\Gamma \rightarrow \mathrm{Q}, \mathrm{Q} \rightarrow \mathrm{P}$, and near Q, respectively. Other small contributions due to the resonance of $\sigma^{*}$ transitions of adsorbed molecules can be present around $300 \mathrm{eV}$ and around $296.5 \mathrm{eV}$, but they are believed to be negligible after heat treatment. In the high energy range, contributions to multiple and single scattering interfere with the transitions and the analysis have not been continued above $320 \mathrm{eV}$. Dramatic changes occur with incidence of the polarisation light onto the substrate, as displayed in Figure 4 and Figure 6. At normal incidence, the $C 1 \mathrm{~s} \rightarrow \pi^{*}$ transition A almost disappears, consistent with the orthogonality of the electric field vector with the orientation of the $\pi^{*}$ orbitals.

The small intensity of transition A observed may be explained by incomplete polarisation or by a small sample misalignment. Two parameters $S(\alpha)$ and $H(\alpha)$ are defined to determine more quantitatively the respective contributions of the $\sigma^{*}$ and $\pi^{*}$ transitions at incidence angle $\alpha . S$ is deduced from the fitting of the carbon absorption spectra by the ratio of the intensity (surface) of $\pi$-type features $(A+C+K+H)$ over $\sigma$-type features $(B+D+E+F+G+L)$. It is expected to be maximum and minimum when graphite is recorded at a grazing and a normal incidence, respectively. In agreement, $S / /$ and $S \perp$ are quoted to 0.93 and 0.08 , respectively (Table 4). $H(\alpha)$ is another ratio of the heights of $A$ feature by $B$ feature, characteristic of both symmetries. It is expected this ratio yield a crude estimation of the orientation effect.

\subsection{Carbon Nanotubes XAS Spectra}

We examine now different carbon nanostructures at GI and NI incidences, respectively. 

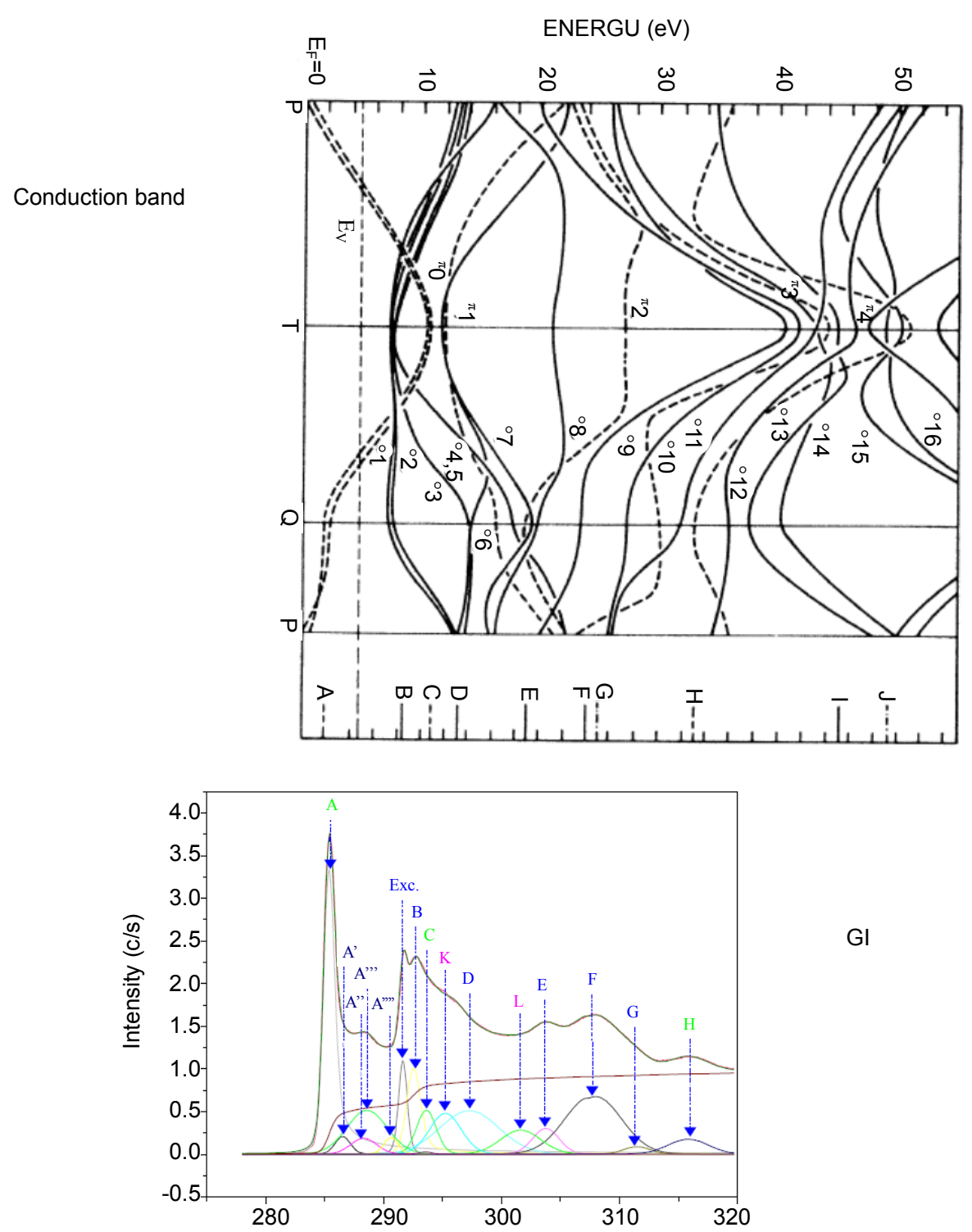

GI

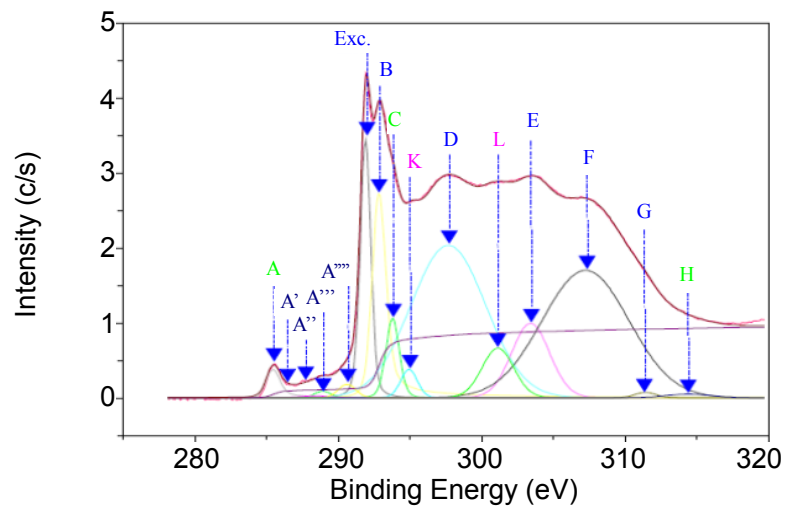

Figure 4. XAS (carbon K edge) of HOPG at grazing (GI) and normal (NI) incidences, respectively. HOPG was preliminary in situ treated at $500^{\circ} \mathrm{C}$. On top, the conduction band of graphite is displayed at the same scale, obtained from calculations of ref. [36]. The features of the XAS spectra are analyzed with regard to the more probable energy level of the UDOS states given on the bottom of the band diagram. 
Table 3. Main features of carbon K edge on HOPG at grazing (GI) and normal (NI) incidence according to shape analysis displayed in Figure 4.

\begin{tabular}{cccccl}
\hline Feature & GI & NI & Literature & Ref. & Assignation \\
\hline A & 285.5 & 285.4 & 285.5 & 29 & $\pi_{0}$ near Q \\
A' & 286.6 & 287.8 & 286.5 & $22,23,27,30,36,43$ & Free Electron-Like Interlayer States $+\pi^{*} \mathrm{C}=\mathrm{C}-\mathrm{OH}$ or $-\left(\mathrm{C}=\mathrm{C}-\pi^{*} \mathrm{C}=\mathrm{O}\right)-$ \\
A $^{\prime}$ & 288.4 & 288.4 & 288.4 & $22,23,27,36,43$ & $\pi^{*} \mathrm{C}=\mathrm{O}$ \\
A $^{\prime \prime}$ & 288.8 & 288.7 & 289.3 & $22,23,27,28,32,43$ & $\sigma^{*} \mathrm{C}-\mathrm{H}+-\left(\mathrm{HO}-\pi^{*} \mathrm{C}=\mathrm{O}\right)$ \\
A $^{\prime \prime}$ & 290.7 & 290.6 & 290.7 & 27,28 & $\sigma^{*} \mathrm{C}-\mathrm{O}$ \\
C-H & 291.8 & 291.8 & 291.8 & $23,24,30,43$ & Exciton \\
B & 292.5 & 292.6 & 292.8 & 29,30 & $\sigma_{1}, \sigma_{2}: \Gamma \rightarrow \mathrm{Q}+$ dipole-allowed \\
C + K & 295.5 & 293.8 & 293.8 & 29 & $\pi_{0}$ or $\pi_{1}$ near $\Gamma+\sigma \mathrm{C}$-O $(\mathrm{H})$ \\
D & 297.8 & 297.5 & 297.7 & 29 & $\sigma_{3}-\sigma_{6}: \mathrm{Q} \rightarrow \mathrm{P}$ \\
E+ L & 303.5 & 302.7 & 302.6 & 29 & $\sigma_{7}$ near Q \\
F & 307.5 & 307.9 & 307.2 & 29 & $\sigma_{9}$ near Q \\
G & 308.5 & 311.4 & 311.4 & 29 & $\sigma_{10}$ near Q \\
H & 316.5 & 315.8 & 314.8 & 29 & $\pi_{4}$ near Q \\
\hline
\end{tabular}

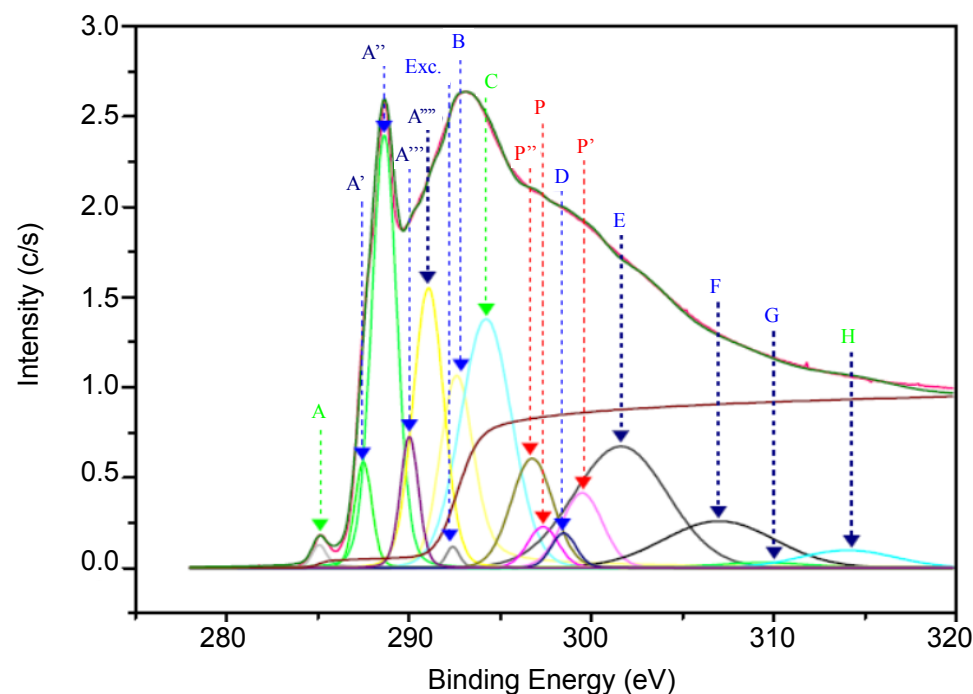

(a)

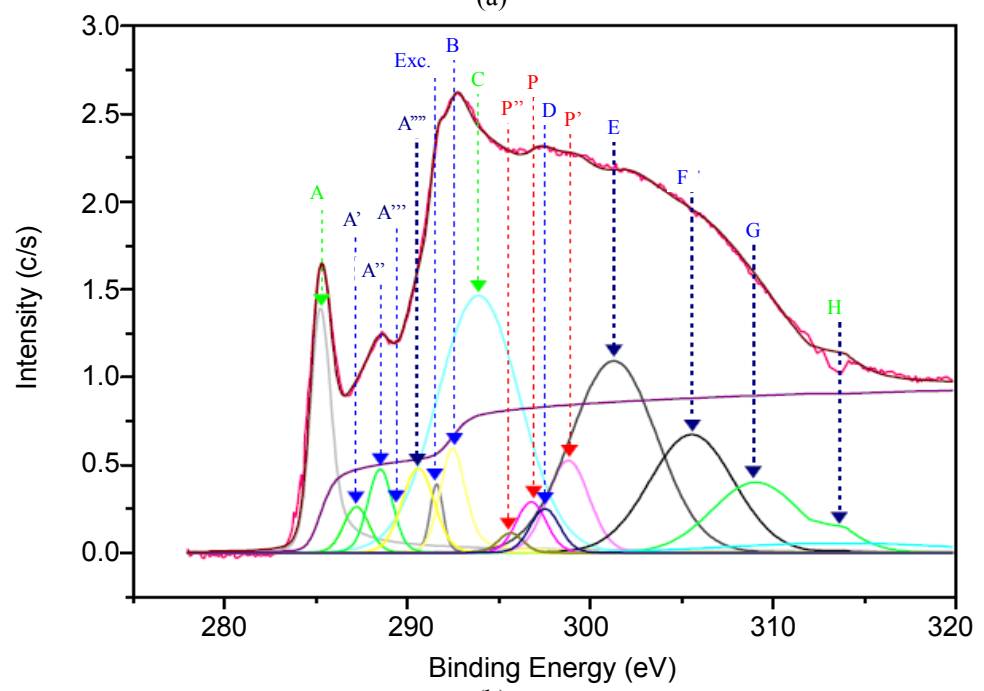

(b)

Figure 5. XAS on the carbon K edge on sample III before and after an in situ thermal treatment at $500^{\circ} \mathrm{C}$ at grazing incidence. 


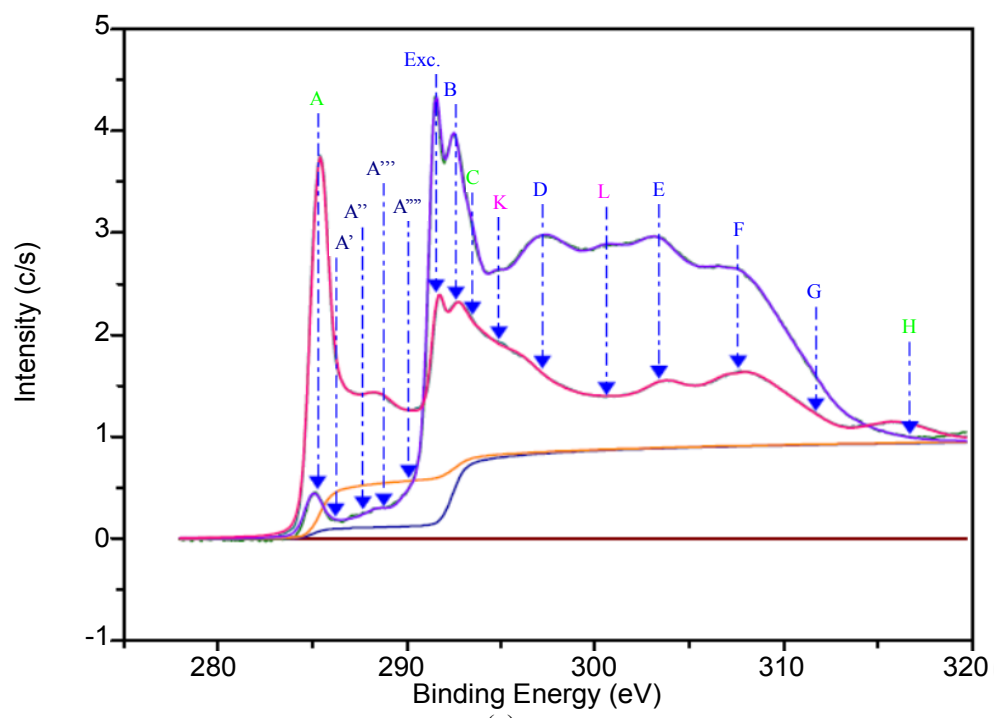

(a)

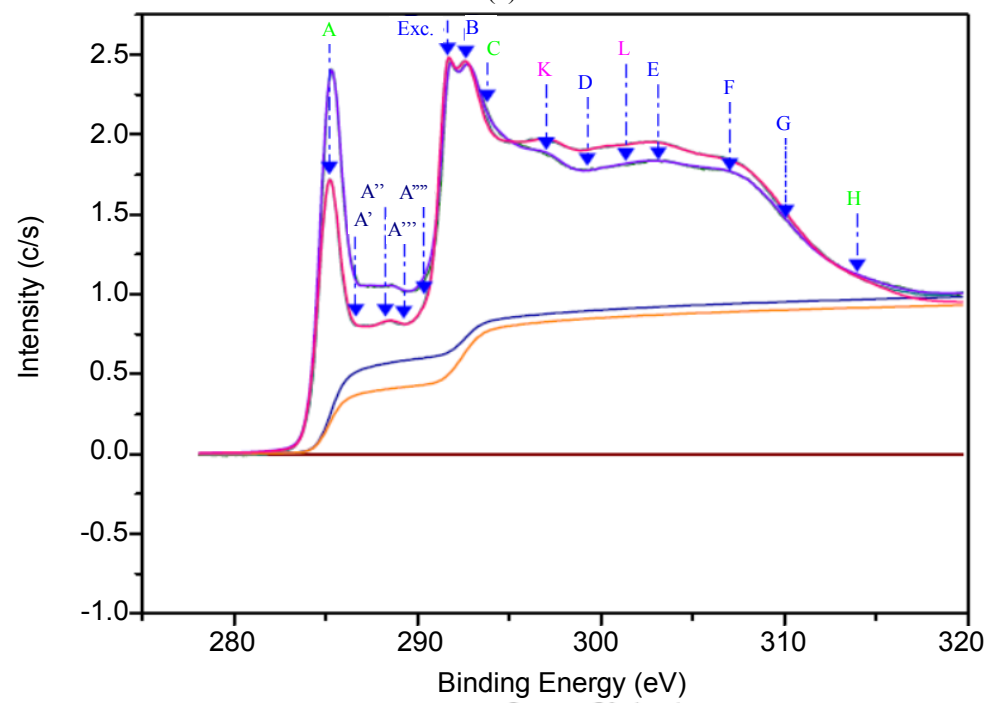

(b)

Figure 6. XAS on the carbon K edge on (a) HOPG graphite and (b) sample VII. In red the incidence is grazing and in black the incidence is normal to the sample. The spectra are normalized. The threshold towards the continuum states is also displayed.

\subsubsection{Heat Treatment}

The effect of a thermal treatment can be dramatic on the shape of the carbon $\mathrm{K}$ edge absorption spectra. This is illustrated in Figure 5 XAS on the carbon K edge of sample III before and after an in situ thermal treatment at $500^{\circ} \mathrm{C}$ at GI. In the $286-291$ energy range, intense contributions due to a high content of adsorbed molecules, like water, $\mathrm{CO}_{2} \cdots$ can be detected, to the detriment of the transitions to the $\pi^{*}$ states (contribution A).

After a high vacuum thermal treatment at $500^{\circ} \mathrm{C}$ for 3 hours, an absorption spectrum closely resembling to the absorption spectrum of graphite is recorded. Thus two conclusions can be derived from this study: i) XAS absorption spectra are a very sensitive and localized probe of the adsorption on carbon nanostructures and ii) it is required to degas the samples preliminary to a true study of the XAS transitions in carbon nanostructures.

It must be noted that the degassing conditions might not be the same for each carbon nanostructures. Thus it was found (not shown) that the nanostructures that display surface sites not only of the basal plane but also primatic sites, like the graphene arranged in platelet or herringbone in samples I and III, require higher treatment temperatures. 
Table 4. Degree of orientation deduced from expression $\{3\}$ for carbon nanostructures. $/ /$ and $\perp$ subscripts denote GI and NI incidence, respectively.

\begin{tabular}{|c|c|c|c|c|c|c|c|}
\hline Sample & $S_{/ /}$ & $S_{\perp}$ & $H_{\| /}$ & $\boldsymbol{H}_{\perp}$ & $\mathrm{I}_{\mathrm{CNS}}(\mathrm{GI}) / I_{G}(\mathrm{GI})$ & $\mathrm{I}_{\mathrm{CNS}}(\mathrm{NI}) / I_{G}(\mathrm{GI})$ & Degree of orientation $R$ \\
\hline HOPG graphite & 0.93 & 0.08 & 3.78 & 0.15 & 1 & 0.04 & -2 \\
\hline $\mathbf{I}$ & 1.02 & 0.92 & 1.8 & 1.55 & 0.48 & 0.41 & $-0,23$ \\
\hline II & 0.96 & 0.86 & 2.7 & 2.2 & 0.53 & 0.71 & -0.23 \\
\hline III & 0.88 & 0.97 & 1.4 & 1.5 & $\begin{array}{l}0.37 \\
0.50\end{array}$ & $\begin{array}{l}0.40 \\
0.54\end{array}$ & 0.21 \\
\hline IV & 0.94 & 1.18 & 1.35 & 1.75 & 0.36 & 0.46 & 0.56 \\
\hline $\mathrm{V}$ & 1.12 & 0.99 & 2.05 & 1.9 & 0.53 & 0.48 & $-0,30$ \\
\hline VI & 0.64 & 0.9 & 1.3 & 1.7 & 0.34 & 0.45 & 0.61 \\
\hline VII & 0.78 & 0.73 & 1.95 & 2 & 0.51 & 0.53 & 0.12 \\
\hline VIII & 0.66 & 0.98 & 1.5 & 2.15 & 0.40 & 0.57 & 0.75 \\
\hline IX & 0.73 & 0.72 & 1.40 & 1.40 & 0.37 & 0.37 & -0.02 \\
\hline
\end{tabular}

\subsubsection{Angular Dependence}

Figure 5(b) shows that the carbon K edge of carbon nanostructures display mainly similar features as HOPG.

From shape analysis of the spectrum the same contributions in the three regions described above can be observed. The main difference comes from a general broadening of the contributions, except the molecular states, that smears out the spectra. This is in agreement with previously reported XAS studies [23] as well as with electron energy-loss spectroscopy (EELS) study [44]. Moreover the contribution A is by far less intense than in HOPG graphite. The comparatively low intensity of the $1 \mathrm{~s} \rightarrow \pi^{*}$ transition in the XAS may be attributed either to the curvature of the shells, like in nanotubes or nanoparticles, or a finite size of the sheets, like in nanofibers or nanowalls. This reduces the interaction among $\pi$ orbitals in the nanotubes. The curvature of the graphite sheet is also among one of the factors which was considered to explain the change of the electronic states in CNTs [45]. Another explanation would be that they are dependent on the incidence of the light due to the strongly oriented character of the carbon nanostructures.

Taking into consideration a random orientation of the carbon nanostructures, the XAS spectra would not be dependent on the incident light and the intensity of the feature A may be compared with that of HOPG measured at the magic angle $54.7^{\circ}$ where no polarization dependence of $\pi$-type states occurs. Both these two points were checked on some samples, like the CNFs or CNPs or even poorly oriented CNTs. To ascertain the second point we evaluate the ratio of intensity of the A line in each carbon nanostructure ICNS compared to the intensity of the line A of HOPG at GI, IG(GI). With a random orientation, $I_{\mathrm{CNS}} / I_{G}(G I)=1 / 3$. Results are reported in Table 4. Values slightly superior to $1 / 3$ are generally obtained, generally between $1 / 3$ and $1 / 2$. The observed broadening of the $\pi^{*}$-band was attributed to the curvature of the graphite shells in CNTs [46] [47]. A complete analysis of the orientation-dependent absorption spectrum for carbon nanostructures with variable orientation of the graphene sheets or graphene shells inside is performed in annex 1. In this geometrical modelization, the curvature of carbon on top of the carbon nanostructures is neglected. This could be non negligible in normal incidence. Also are neglected the possible interactions of carbon with the metallic catalyst, with possible charge transfer and therefore modification of the UDOS of carbon. Thus photoemission measurements found that at the tip, the $\mathrm{C} 1 \mathrm{~s}$ core level could shift to a higher binding energy and the density of states (DOS) at the Fermi level, Ef, was enhanced [48] [49]. However this effect is rather weak. It is thus believed that the effects of both interactions lead to a broadening of the $\pi^{*}$ - and $\sigma^{*}$-band features in the absorption spectra of the carbon nanostructures. Let's take the case of a nanotube. The intensity at GI $\left(\alpha=\alpha_{M}\right)$ of a nanotube normal to the surface $(\theta=0)$ is given by:

$$
I_{\mathrm{CNT}}\left(\alpha_{m}, 0,0,0\right)=\frac{\mathrm{NI}_{\pi}^{0}}{4}\left\{\left[\left(1-3 \cos ^{2} \alpha_{m}\right)\right]+\left(1+\cos ^{2} \alpha_{m}\right)\right\}
$$


whereas the intensity at NI $\left(\alpha=\alpha_{m}\right)$ is

$$
I_{\mathrm{CNT}}\left(\alpha_{M}, 0,0,0\right)=\frac{\mathrm{NI}_{\pi}^{0}}{4}\left\{\left[\left(1-3 \cos ^{2} \alpha_{M}\right)\right]+\left(1+\cos ^{2} \alpha_{M}\right)\right\} .
$$

Then we define a factor of alignment $R$ of carbon $\pi$ orbitals normal to the surface as

$$
R=-2\left\{\frac{\left[I_{\mathrm{CNT}}\left(\alpha_{M}, 0,0,0\right)-I_{\mathrm{CNT}}\left(\alpha_{m}, 0,0,0\right)\right]}{\left[I_{G}\left(\alpha_{M}, 0,0,0\right)-I_{G}\left(\alpha_{m}, 0,0,0\right)\right]}\right\} .
$$

The absorption intensities are rated by reference to the absorption intensity in HOPG graphite $I_{G}$ where the orientation of $\pi$ orbitals is well defined. Taking the area of the absorption contributions of CN and HOPG, respectively, as a measurement of the resonance to $\pi$-orbitals

$$
R \approx-2\left\{\left[S_{\perp}^{\mathrm{CN}}-S_{/ /}^{\mathrm{CN}}\right]-\left[S_{\perp}^{G}-S_{/ /}^{G}\right]\right\} .
$$

And more generally for a nanostructure $I_{\mathrm{CN}}(\alpha, \beta, \gamma, \theta)$

$$
R=-2\left\{\frac{\left[I_{\mathrm{CN}}\left(\alpha_{M}, \beta, \gamma, \theta\right)-I_{\mathrm{CN}}\left(\alpha_{m}, \beta, \gamma, \theta\right)\right]}{\left[I_{G}\left(\alpha_{M}, \beta, \gamma, \theta\right)-I_{G}\left(\alpha_{m}, \beta, \gamma, \theta\right)\right]}\right\} .
$$

In the limiting case where, $\alpha_{M}=\pi / 2$ and $\alpha_{m}=0$ then

$$
I_{\mathrm{CNT}}(\pi / 2,0,0,0)=\mathrm{NI}_{0}^{\pi / 2} \text { and } I_{\mathrm{CNT}}(0,0,0) \text {. }
$$

Here the factor 2 takes into consideration that the $\pi$ orbitals are randomly oriented in the azimuthal direction of the carbon nanotube. The negative sign indicates that the $\pi$ orbitals are rotated by $\pi / 2$ by reference with the orbitals of graphite.

Values of $R$ calculated from Equation (4) are reported in Table 4. It can be seen that only the CNTs exhibit a clear degree of orientation that however in the best case do not exceed $70 \%$. Good agreement is obtained between the good alignment observed in CNTs of samples IV, VI and VIII by SEM and the degree of orientation extracted from XAS well above $50 \%$. Reversely a poorly aligned CNTs sample like sample VII exhibits a much smaller degree of alignment around $20 \%$. Probably also in this sample the aspect ratio is low and thus the contribution of carbon atoms at the cap of the CNT is not negligible. The case of sample II is even more suggestive as the $R$ value is negative, which means that nanotube is rather aligned parallel to the surface of the sample. This is rather in agreement with SEM observations. As expected, the carbon nanoparticles (sample V) yield no special degree of alignment. In the case of nanowalls (sample VIII) a weak degree of alignment, at the limit of detection, is observed. This means that the walls are poorly oriented in the direction normal to the surface and that the graphene sheets are in fact rather randomly distributed in the polar direction. The case of samples I and III deserves more attention. A negative but weak mutual orientation can be observed on sample (I). This is in line with TEM and SEM observations where graphene sheets are observed rather parallel to the substrate, but the extent to which this mutual orientation occurs remains weak. On the other hand on sample III as expected the absorption spectra exhibit a positive degree of alignment, but again to a weaker extent as expected from the TEM observations. Thus probably it can be explained by inhomogeneities of the sample, to the presence of defects inside the graphene and to some remaining adsorbates at the surface carbon sites of the nanostructure. A last point to be discussed concerns the influence of the carbon cap that generally ends up the top carbon of the nanostructure. The absorption spectra might be sensitive to this carbon cap, especially in the NI as the PEY detection mode of electrons is surface sensitive. Let us recall that in the model developed in Annex 1, we account only for sidewall carbons and not of top carbons. Accounting for the curvature of the $\pi$ orbitals on top of the nanostructure, this will imply a decrease of $I_{\mathrm{CNT}}\left(\alpha_{M}, 0,0,0\right)$ intensity and an increase of $I_{\mathrm{CNT}}\left(\alpha_{m}, 0,0,0\right)$ intensity in Equation (3). Thus this will contribute to markedly decrease the estimation of the degree of alignment. Thus the degree of orientation determined by Equation (3) is an estimation by defect of the true degree of alignment. Accounting for the tip effect on the absorption spectra requires to know both the electron escape from the XANES measurements and geometrical parameters of the carbon nanostructures like diameter, length, 
density. Anyway the total extinction of the $\pi^{*}$ band cannot be observed even at glancing incidence. However the non extinction of the $\pi^{*}$ band at glancing incidence may also be attributed to the sample misalignment, to the misalignment of CNTs relative to the surface normal or to contributions steaming from other carbon species present on the sample.

\section{Conclusions}

We have performed a quantitative C K-edge XAS study of the orientation of oriented carbon nanostructures (nanotubes, nanofibers, nanoparticles, nanowall with different orientation of the graphene sheets or shells can be prepared). They are grown on plain $\mathrm{SiO}_{2}(8 \mathrm{~nm}$ thick $) / \mathrm{Si}(100)$ substrates by a Plasma and Hot Filaments-enhanced Catalytic Chemical Vapor Deposition (PE HF CCVD) process. Using the highly oriented pyrolytic graphite (HOPG) as a starting point model for the understanding of the CNTs properties, we have first recorded and analyzed the HOPG XAS spectra. While applying the C K-edge XAS to the CNTs orientation characterization, we find spectral features very similar to those of HOPG, in agreement with the literature. The XAS spectra are highly sensitive to a previous thermal treatment, as an intense adsorption on the outer wall of the nanotubes may strongly affect the absorption transitions. The morphology and the nature of these carbon nanostructures are characterized by SEM, TEM and Raman spectroscopy. From the angular dependence of the incident light and geometrical morphology of the nanostructures, wide variations of the $\mathrm{C} \mathrm{K}$-edge intensity of the transitions to the empty $\pi^{*}$ and $\sigma^{*}$ states occur. A full lineshape analysis of the XAS spectra has been carried out using a home-made software, allowing estimating the relative proportion of $\pi^{*}$ and $\sigma^{*}$ transitions. A geometrical model of the angular dependence with the incidence angle of the light and the morphology of the carbon nanostructures is derived. With normalization to the HOPG graphite reference case, a degree of alignment can be extracted which is representative of the localized orientation of the graphitic carbon $\pi$ bonds, accounting not only for the overall orientation, but also for local defects like impurities incorporation, structural defects ... This degree of alignment shows good agreement with SEM observations. Thus CNTs films display degrees of alignment around $50 \%$, depending on the occurrence of defects in the course of the growth, whereas no special alignment can be detected with CNFs and CNPs, and a weak one (about 20\%) is detected on CNWs.

More attention must be deserved to the contribution of capped carbon in addition to carbon sidewalls constituting the major part of these carbon nanostructures.

\section{Acknowledgements}

P. Legagneux (Thales $\mathrm{R} \S \mathrm{D}$, Orsay) is acknowledged for providing the $\mathrm{SiO} 2 / \mathrm{Si}(100)$ samples; $\mathrm{M}$. Accosta and $\mathrm{G}$. Schmerber for sample preparation by sputtering. One of the authors is indebted for a fund from the French Ministry of Foreign Affairs and another one from the AUEF.

\section{References}

[1] Iijima, S. (1991) Helical Microtubules of Graphitic Carbon. Nature, 354, 56-58. http://dx.doi.org/10.1038/354056a0

[2] Groning, O., Kuttel, O.M., Emmenegger, C., Groning, P. and Schlapbach, L. (1999) Field Emission Properties of Carbon Nanotubes. Journal of Vacuum Science \& Technology B: Microelectronics and Nanometer Structures, 18, 665. http://dx.doi.org/10.1116/1.591258

[3] Dresselhaus, M.S., Dresselhaus, G. and Avouris, P. (2001) Carbon Nanotubes: Synthesis, Structure, Properties and Applications. Springer, Berlin, 29. http://dx.doi.org/10.1007/3-540-39947-X

[4] Wei, Y., Xie, C., Dean, K.A. and Coll, B.F. (2001) Stability of Carbon Nanotubes under Electric Field Studied by Scanning Electron Microscopy. Applied Physics Letters, 79, 4527-4529. http://dx.doi.org/10.1063/1.1429300

[5] Dai, L.M., Patil, A., Gong, X., Guo, Z., Liu, L., Liu, Y. and Zhu, D. (2003) Aligned Nanotubes. ChemPhysChem, 4, 1150-1169. http://dx.doi.org/10.1002/cphc.200300770

[6] Mane Mane, J., Cojocaru, C.S., Barbier, A., Deville, J.P., Sendja, T. and Le Normand, F. (2007) GISAXS Study of Carbon Nanotubes Grown by CVD. Physica Status Solidi (a), 204, 4209-4229.

[7] Cao, A., Xu, C., Liang, J., Wu, D. and Wie, B. (2001) X-Ray Diffraction Characterization on the Alignment Degree of Carbon Nanotubes. Chemical Physics Letters, 344, 13. http://dx.doi.org/10.1016/S0009-2614(01)00671-6

[8] Pinault, M., Pichot, P., Khodja, H., Launois, P., Mayne-L’Hermite, M. and Reynaud, C. (2005) Evidence of Sequential Lift in Growth of Aligned Multiwalled Carbon Nanotube Multilayers. Nano Letters, 5, 2394-2398.

http://dx.doi.org/10.1021/n1051472k 
[9] Comelli, G., Stohr, J., Jark, W. and Pate, B.B. (1988) Extended X-Ray-Absorption Fine-Structure Studies of Diamond and Graphite. Physical Review B, 37, 4383-4389. http://dx.doi.org/10.1103/PhysRevB.37.4383

[10] Yang, X.Q., Ruckman, M.W., Skotheim, T.A., Den Boer, M., Zheng, Y., Badzian, A.R., Badzian, T., Messier, R. and Srivatsa, A.R. (1991) Optical spectroscopic investigation of segmented trans-polyacetylene. Journal of Vacuum Science \& Technology A: Vacuum, Surfaces, and Films, 9, 1140. http://dx.doi.org/10.1116/1.577591

[11] Edamatsu, K., Takata, Y., Yokoyama, T., Seki, K., Tohnan, M., Okada, T. and Ohta, T. (1991) Local Structures of Carbon Thin Films Synthesized by the Hot Filament Chemical Vapor Deposition Method X-Ray-Absorption NearEdge Structure and Raman Spectroscopic Studies. Japanese Journal of Applied Physics, 30, 1073-1083. http://dx.doi.org/10.1143/JJAP.30.1073

[12] Fayette, L., Marcus, B., Mermoux, M., Tourillon, G., Parent, P., Laffon, K. and Le Normand, F. (1998) Local Order in CVD Diamond Films: Comparative Raman, X-Ray-Diffraction and X-Ray-Absorption Near-Edge Studies. Physical Review B, 57, 14123-14132. http://dx.doi.org/10.1103/PhysRevB.57.14123

[13] Garcia, M.M., Jimenez, I., Vazquez, L.K., Gomez-Aleixandre, C., Albella, J.M., Sanchez, O., Terminello, L.J. and Himpsel, F.J. (1998) X-Ray Absorption Spectroscopy and Atomic Force Microscopy Study of Bias-Enhanced Nucleation of Diamond Films. Applied Physics Letters, 72, 2105. http://dx.doi.org/10.1063/1.121290

[14] Jimenez, I., Mar Garcia, M., Albella, J.M. and Terminello, L.J. (1998) Orientation of Graphitic Planes during the Bias-Enhanced Nucleation of Diamond on Silicon: An X-Ray Absorption Near-Edge Study. Applied Physics Letters, 73, 2911. http://dx.doi.org/10.1063/1.122627

[15] Ripalda, J.M., Roman, E., Diaz, N., Galan, L., Montero, I., Comelli, G., Baraldi, A., Lizzit, S., Goldoni, A. and Paolucci, G. (1999) Correlation of X-Ray Absorption and X-Ray Photoemission Spectroscopies in Amorphous Carbon Nitride. Physical Review B, 60, R3705-R3708. http://dx.doi.org/10.1103/PhysRevB.60.R3705

[16] Shimoyama, I., Wu, G., Sekiguchi, T. and Baba, Y. (2000) Evidence for the Existence of Nitrogen-Substituted Graphite Structure by Polarization Dependence of Near-Edge X-Ray-Absorption Fine Structure. Physical Review B, 62, R6053-R6056. http://dx.doi.org/10.1103/PhysRevB.62.R6053

[17] Jimenez, I., Gago, R., Albella, J.M., Caceres, D. and Vergara, I. (2000) Spectroscopy of П Bonding in Hard Graphitic Carbon Nitride Films: Superstructure of Basal Planes and Hardening Mechanisms. Physical Review B, 62, 4261-4264. http://dx.doi.org/10.1103/PhysRevB.62.4261

[18] Mubumbila, N., Bouchet-Favre, B., Godon, C., Marhic, C., Angleraud, B., Tessier, P.Y. and Minea, T. (2004) EELS and NEXAFS Structural Investigations on the Effects of the Nitrogen Incorporation in a-CN $\mathrm{C}_{x}$ Films Deposited by R.F. Magnetron Sputtering. Diamond and Related Materials, 13, 1433-1436. http://dx.doi.org/10.1016/j.diamond.2003.11.055

[19] Hellgren, N., Guo, J., Luo, Y., Sathe, C., Agui, A., Kashtanov, S., Nordgren, J., Agren, H. and Sundgren, J.E. (2005) Electronic Structure of Carbon Nitride Thin Films Studied by X-Ray Spectroscopy Techniques. Thin Solid Films, 471, 19-34. http://dx.doi.org/10.1016/j.tsf.2004.03.027

[20] Comelli, G., Stohr, J., Robinson, C.J. and Jark, W. (1988) Structural Studies of Argon-Sputtered Amorphous Carbon Films by Means of Extended X-Ray-Absorption Fine Structure. Physical Review B, 38, 7511-7519. http://dx.doi.org/10.1103/PhysRevB.38.7511

[21] Gago, R., Jimenez, I. and Albella, J.M. (2001) Detecting with X-Ray Absorption Spectroscopy the Modifications of the Bonding Structure of Graphitic Carbon by Amorphisation, Hydrogenation and Nitrogenation. Surface Science, 482-485, 530-536. http://dx.doi.org/10.1016/S0039-6028(01)00939-6

[22] Yueh, C.L., Chiou, J.W. and Pong, W.F. (2001) Electronic Structure of the Fe-Layer-Catalyzed Carbon Nanotubes Studied by X-Ray-Absorption Spectroscopy. Applied Physics Letters, 79, 3179. http://dx.doi.org/10.1063/1.1416165

[23] Imamura, M., Shimada, H., Matsubayashi, H., Yumura, M., Uchida, K., Oshima, S., Kuriki, Y., Yoshimura, Y., Yoshimura, Y., Sato, T. and Nishijima, A. (1994) Electron Energy-Loss Spectra of Single-Shell Carbon Nanotubes. Japanese Journal of Applied Physics, 33, L1316-L1319. http://dx.doi.org/10.1143/JJAP.33.L1316

[24] Coffman, F.L., Cao, R., Pianetta, P.A., Kapoor, S., Kelly, M. and Terminello, L.J. (1996) Near-Edge X-Ray Absorption of Carbon Materials for Determining Bond Hybridization in Mixed sp2/sp3 Bonded Materials. Applied Physics Letters, 69, 568-570. http://dx.doi.org/10.1063/1.117789

[25] Tang, Y.H., Zhang, P., Kim, P.S., Sham, T.K., Hu, Y.F. and Sun, X.H., et al. (2001) Amorphous Carbon Nanowires Investigated by Near-Edge-X-Ray-Absorption-Fine-Structures. Applied Physics Letters, 69, 3773. http://dx.doi.org/10.1063/1.1425462

[26] Enouz, S., Bantignies, J.L., Babaa, M.R., Alvarez, L., Parent, P., Le Normand, F., Stéphan, O., Poncharal, P., Loiseau, A. and Doyle, B.P. (2007) Spectroscopic Study of Nitrogen Doping of Multi-Walled Carbon Nanotubes. Journal of Nanoscience and Nanotechnology, 7, 3524-3527. http://dx.doi.org/10.1166/jnn.2007.839

[27] Kuznetsova, A., Popova, I., Yates, J.T., Bronikowski, M.J., Huffman, C.B., Liu, J., Smalley, R.E., Hwu, H.H. and 
Chen, J.G. (2001) Oxygen-Containing Functional Groups on Single-Wall Carbon Nanotubes: NEXAFS and Vibrational Spectroscopic Studies. Journal of the American Chemical Society, 123, 10699-10704. http://dx.doi.org/10.1021/ja011021b

[28] Babaa, M.-R., Bantignies, J.-L., Alvarez, L., Parent, P., Le Normand, F., Gulas, M., Mane Mane, J., Poncharal, P. and Doyle, B.P. (2007) NEXAFS Study of Multi-Walled Carbon Nanotubes Functionalization with Sulfonated Poly(ether ether ketone) Chains. Journal of Nanoscience and Nanotechnology, 7, 3463-3467. http://dx.doi.org/10.1166/jnn.2007.816

[29] Rosenberg, R.A., Love, P.J. and Rehn, V. (1986) Polarisation-Dependant Near-Edge X-Ray-Absorption Fine Structure of Graphite. Physical Review B, 33, 4034-4037. http://dx.doi.org/10.1103/PhysRevB.33.4034

[30] Batson, P.E. (1993) Carbon 1s Near-Edge-Absorption Fine Structure in Graphite. Physical Review B, 48, $2608-2610$. http://dx.doi.org/10.1103/PhysRevB.48.2608

[31] Bruhwiler, P.A., Karis, O. and Martensson, N. (2002) Charge-Transfer Dynamics Studied Using Resonant Core Spectroscopies. Reviews of Modern Physics, 74, 703-740. http://dx.doi.org/10.1103/RevModPhys.74.703

[32] Stöhr, J. (1992) NEXAFS Spectroscopy. Springer, Berlin. http://dx.doi.org/10.1007/978-3-662-02853-7

[33] Schiessling, J., Kjeldgaard, L., Rohmund, F., Falk, L.K.L., Campbell, E.E.B., Nordgren, J. and Bruhwiler, P.A. (2003) Synchrotron Radiation Study of the Electronic Structure of Multiwalled Carbon Nanotubes. Journal of Physics: Condensed Matter, 15, 6563-6579. http://dx.doi.org/10.1088/0953-8984/15/38/022

[34] Banerjee, S., Hemraj-Benny, T., Sambavisan, S., Fischer, D.A., Misewich, J.A. and Wong, S.S. (2005) Near-Edge X-Ray Absorption Fine Structure Investigations of Order in Carbon Nanotube-Based Systems. The Journal of Physical Chemistry B, 109, 8489-8495. http://dx.doi.org/10.1021/jp047408t

[35] Minea, T., Bouchet-Fabre, B., Lazar, S., Point, S. and Zandbergen, H.W. (2006) Angular and Local Spectroscopic Analysis to Probe the Vertical Alignment of N-Doped Well-Separated Carbon Nanotubes. The Journal of Physical Chemistry B, 110, 15659-15662. http://dx.doi.org/10.1021/jp0637072

[36] Chiou, J.W., Yueh, C.L., Jan, J.C., Tsai, H.M., Pong, W.F., et al. (2002) Electronic Structure of the Carbon Nanotube Tips Studied by X-Ray-Absorption Spectroscopy and Scanning Photoelectron Microscopy. Applied Physics Letters, 81, 4189. http://dx.doi.org/10.1063/1.1523152

[37] Cojocaru, C.S., Senger, A. and Le Normand, F. (2006) A Nucleation and Growth Model of Vertically-Oriented Carbon Nanofibers or Nanotubes by Plasma-Enhanced Catalytic Chemical Vapor Deposition. Journal of Nanoscience and Nanotechnology, 6, 1331-1338. http://dx.doi.org/10.1166/jnn.2006.144

[38] Cojocaru, C.S. and Le Normand, F. (2006) On the Role of Activation Mode in the Plasma- and Hot Filaments-Enhanced Catalytic Chemical Vapour Deposition of Vertically Aligned Carbon Nanotubes. Thin Solid Films, 515, 53-58. http://dx.doi.org/10.1016/j.tsf.2005.12.137

[39] Mane Mane, J., Cojocaru, C.S., Barbier, A., Deville, J.P., Jean, B., Metzger, T.H., Thiodjio Sendja, B. and Le Normand, F. (2007) GISAXS Study of the Alignment of Oriented Carbon Nanotubes Grown on $\mathrm{Plain}_{\mathrm{SiO}} / \mathrm{Si}(100) \mathrm{Sub}-$ strates by a Catalytically Enhanced CVD Process. Physica Status Solidi (A), 204, 4209-4229. http://dx.doi.org/10.1002/pssa.200723201

[40] Eba Medjo, R., Thiodjio Sendja, B., Mane Mane, J. and Owono Ateba, P. (2009) A Study of Carbon Nanotube Contamination by XANES Spectroscopy. Physica Scripta, 80, Article ID: 045601, 6 p. http://dx.doi.org/10.1088/0031-8949/80/04/045601

[41] Sette, F., Wertheim, G.K., Ma, Y., Meigs, G., Modesti, S. and Chou, C.T. (1990) Lifetime and Screening of the C 1s Photoemission in Graphite. Physical Review B, 41, 9766-9770. http://dx.doi.org/10.1103/PhysRevB.41.9766

[42] Willis, R.F., Fitton, B. and Painter, G.S. (1974) Secondary-Electron Emission Spectroscopy and the Observation of High-Energy Excited States in Graphite: Theory and Experiment. Physical Review B, 9, 1926-1937. http://dx.doi.org/10.1103/PhysRevB.9.1926

[43] Fischer, D.A., Wentzcovitch, R.M., Carr, R.G., Continenza, A. and Freeman, A.J. (1991) Graphitic Interlayer States-A Carbon-K Nearedge X-Ray-Absorption Fine-Structure Study. Physical Review B, 44, 1427-1429. http://dx.doi.org/10.1103/PhysRevB.44.1427

[44] Dravid, V.P., Lin, X., Wang, Y., Wang, X.K., Yee, A., Ketterson, J.B. and Chang, R.P.H. (1993) Buckytubes and Derivatives: Their Growth and Implications for Buckyball Formation. Science, 259, 1601-1602.

[45] Mintmire, J.W., Dunlap, B.I. and White, C.T. (1992) Are Fullerene Tubules Metallic? Physical Review Letters, 68, 631-634. http://dx.doi.org/10.1103/PhysRevLett.68.631

[46] Kuzuo, R., Terauchi, M., Tanaka, M., Saito, Y. and Japn. J. (1994) Electron Energy-Loss Spectra of Single-Shell Carbon Nanotubes. Japanese Journal of Applied Physics, 33, L1316-L1319. http://dx.doi.org/10.1143/JJAP.33.L1316

[47] Hanada, T., Okada, Y. and Yase, K. (1999) The Science and Technology of Carbon Nanotubes. Elsevier, Oxford. 
[48] Suzuki, S., Watanabe, Y., Kiyokura, T., Nath, K.G., Ogino, T., Heun, S., Zhu, W., Bower, C. and Zhou, O. (2001) Electronic Structure at Carbon Nanotube Tips Studied by Photoemission Spectroscopy. Physical Review B, 63, 1-7.

[49] Suzuki, S., Watanabe, Y., Ogino, T., Heun, S., Gregoratti, L., Barinov, A., Kaulich, B., Kiskinova, M., Zhu, W., Bower, C. and Zhou, O. (2002) Electronic Structure of Carbon Nanotubes Studied by Photoelectron Spectromicroscopy. Physical Review B, 66, 1-4. 


\section{Annex}

Full calculation of the angular dependence of the absorption intensity in the case of carbon nanotubes and carbon nanofibers grown on a flat surface.

The absorption transition $P_{\text {if }}$ at the K edge of carbon is given by the gold rule of Fermi [32]:

$$
P_{\text {if }}=(1 / h)|\langle f / V / f\rangle|^{2} \rho_{f}(E)
$$

where $f$ and $i$ are a final and initial states, respectively, $\rho_{f}(E)$ is the density of final states, and $\mathrm{V}$ is a harmonic time-dependant perturbation. Within the dipole selection rule and the spherical wave approximations, this expression rules to

$$
P_{\text {if }}=\left[E_{0}^{2} \pi^{2} \mathrm{e}^{2}(N / h) m^{2} \omega^{2}\right](\mathrm{e} p)=I_{0}^{\pi} N(\mathrm{e} p)
$$

where $E_{0}$ is the electric field amplitude, $\omega$ the wave number of the electromagnetic field, $N$ the atomic density of carbon atoms and $\mathrm{e}, h, m$ have the usual physical meanings. e and $p$ are the unit vector of the electric field and the momentum operator which points in the direction of the final state $\pi^{*}$. We will calculate the last term in the case of carbon nanotubes and carbon nanofibers grown on a flat surface (Scheme 1). We neglect the contribution of the capped carbons on top of the carbon nanostructures.

Let us consider the more general case of carbon nanofibers where the graphitic basal planes are oriented with a conical polar angle $\gamma$ relative to the fiber axis $\boldsymbol{A} \boldsymbol{A}^{\prime}$. In the case of a carbon nanotube, $\gamma=0$ In the case of a carbon nanofiber with a herringbone organization, $\gamma \geq 0$. The angle with the $\pi$ bond direction $c$ is then $(\pi / 2)-\gamma$ whereas the angle with the $\sigma$ bond in the graphitic base plane or shell is $\gamma$. The XAS signal is integrated over all the $\pi$ orbitals along the $\varphi$ azimuthal angle around the axis of the carbon nanostructure. Now these nanofibers are grown on a flat substrate like $\mathrm{SiO}_{2} / \mathrm{Si}(100)$ with a random polar angle $\theta$ relative to the normale axis $\mathrm{ZZ}$ ' to the substrate. With a random orientation normal to the surface, $\theta=0$ When the tubes are lying within the substrate, $\theta=\pi / 2$

Finally the light impinges the surface at an incidence angle $\alpha$ relative to the $(X, Y)$ plane of the substrate with a Poynting polarisation vector $\boldsymbol{P}$ in the $z$ direction and the electric vector $\boldsymbol{E}$ is within the plan $(x, y, 0)$ of the triedre $(x, y, z)$ with an angle $\beta$ relative to an horizontal orientation of the electric field in the propagating light, which is generally encountered in synchrotron light. Thus with $\beta=0^{\circ}$ the light is linearly polarized while with $\beta=45^{\circ}$ the light is circularly polarized. Assuming a general elliptic polarisation of the light $0^{\circ} \leq \beta \leq 45^{\circ}$, the intensity of the absorption with transition to $\pi^{*}$ states of the carbon nanostructures can be expressed by intergrating over all azimuthal angles $\varphi$ :

$$
I_{\pi}(\alpha, \beta, \gamma, \theta)=\frac{\mathrm{NI}_{\pi}^{0}}{4}\left\{\cos ^{2} \theta\left[\left(1-3 \sin ^{2} \gamma\right)\left(1-3 \cos ^{2} \beta \cos ^{2} \alpha\right)\right]+\left(1+\cos ^{2} \beta \cos ^{2} \alpha\right)+\sin ^{2} \gamma\left(1-3 \cos ^{2} \beta \cos ^{2} \alpha\right)\right\}
$$

whereas the transition to $\sigma^{*}$ states $I_{\sigma}(\alpha, \beta, \gamma, \theta)$ can be expressed by changing $\gamma$ for $\gamma+(\pi / 2)$ and multiplying by 3 since there are $3 \sigma$ orbitals for each $\pi$ orbital. The result is then

$$
I_{\sigma}(\alpha, \beta, \gamma, \theta)=\frac{3}{2}\left[1-I_{\pi}(\alpha, \beta, \gamma, \theta)\right]
$$

which in the case of a linearly polarized light with $\beta=0$, the expressions A3 and A4 reduce to

$$
I_{\pi}(\alpha, \beta, \gamma, \theta)=\frac{\mathrm{NI}_{\pi}^{0}}{4}\left\{\cos ^{2} \theta\left[\left(1-3 \sin ^{2} \gamma\right)\left(1-3 \cos ^{2} \alpha\right)\right]+\left(1+\cos ^{2} \alpha\right)+\sin ^{2} \gamma\left(1-3 \cos ^{2} \alpha\right)\right\}
$$

and the same as A4 for $I_{\sigma}(\alpha, 0, \gamma, \theta)$

In the case of HOPG graphite or graphite planes in the nanostructure parallel to the surface $\gamma=\pi / 2$ whereas in the case of a nanotube $\gamma=0$, the expression A5 becomes (A6) and (A7), respectively

$$
\begin{gathered}
I_{\pi}(\alpha, 0, \pi / 2, \theta)=\frac{\mathrm{NI}_{\pi}^{0}}{4}\left\{\cos ^{2} \theta\left[-2\left(1-3 \cos ^{2} \alpha\right)\right]+\left(2-2 \cos ^{2} \alpha\right)\right\} \\
I_{\pi}(\alpha, 0,0, \theta)=\frac{\mathrm{NI}_{\pi}^{0}}{4}\left\{\cos ^{2} \theta\left[\left(1-3 \cos ^{2} \alpha\right)\right]+\left(1+\cos ^{2} \alpha\right)\right\}
\end{gathered}
$$


Scientific Research Publishing (SCIRP) is one of the largest Open Access journal publishers. It is currently publishing more than 200 open access, online, peer-reviewed journals covering a wide range of academic disciplines. SCIRP serves the worldwide academic communities and contributes to the progress and application of science with its publication.

Other selected journals from SCIRP are listed as below. Submit your manuscript to us via either submit@scirp.org or Online Submission Portal.
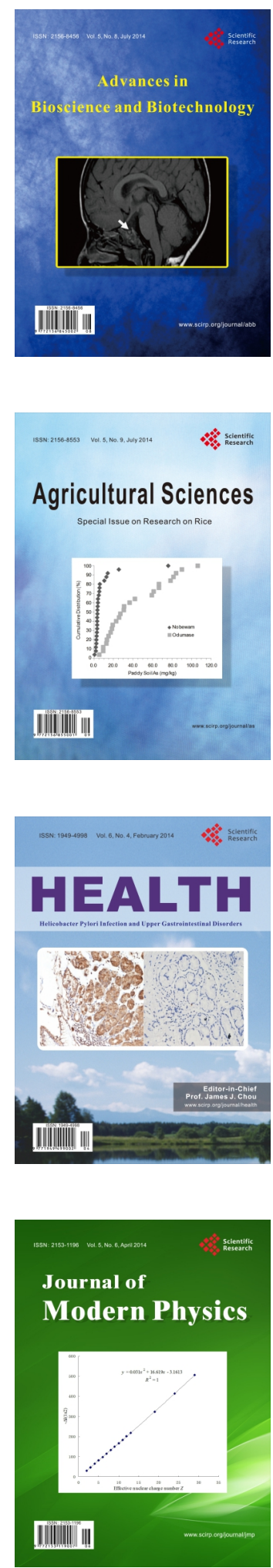
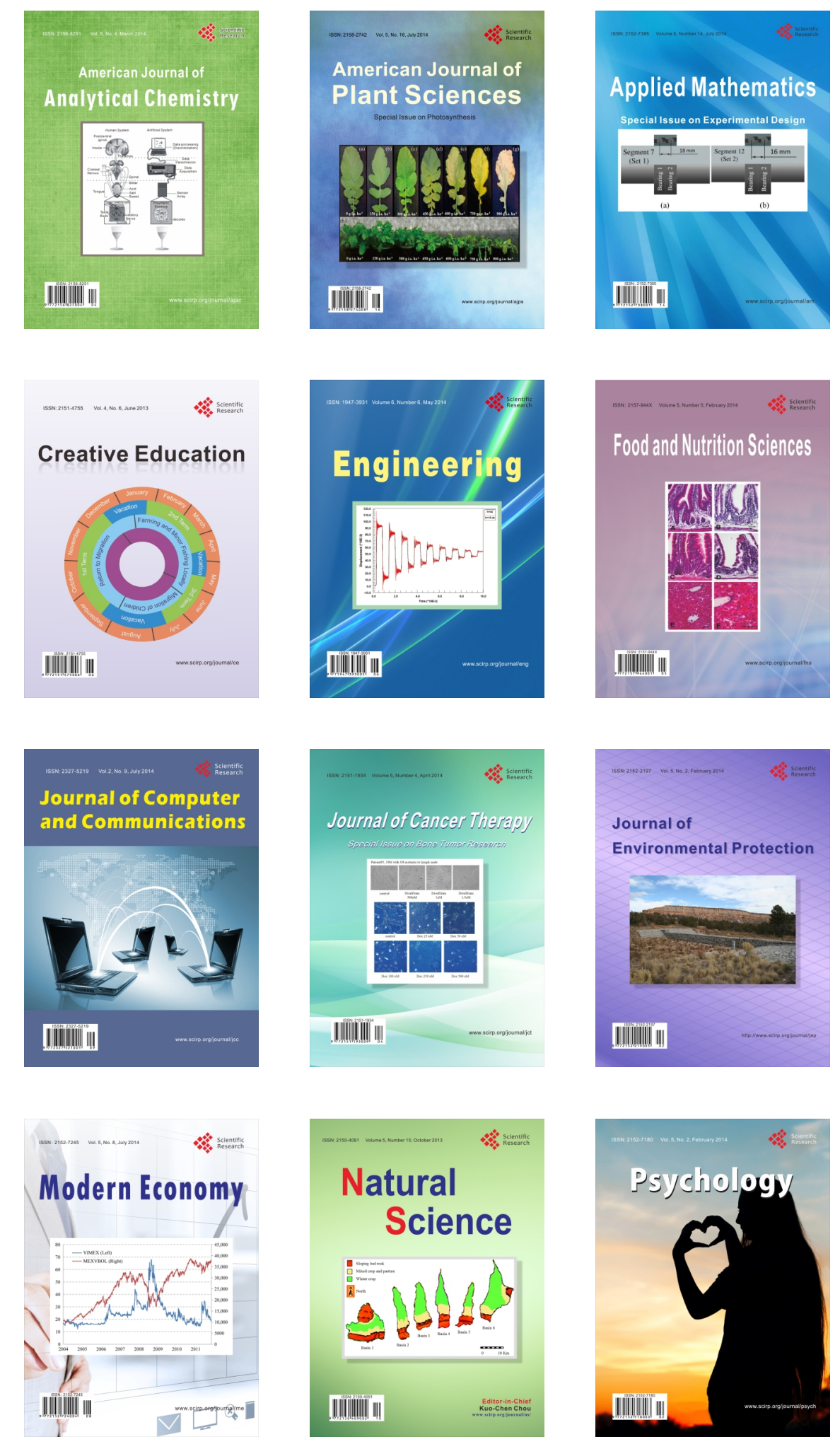